\title{
Depression, Internalized HIV Stigma and HIV Disclosure
}

\author{
Elialilia S. Okello1* , Glenn J. Wagner², Bonnie Ghosh-Dastidar'2, Jeffrey Garnett ${ }^{2}$, \\ Dickens Akena', Noeline Nakasujja1, Seggane Musisi' ${ }^{1}$ \\ ${ }^{1}$ Department of Psychiatry, Makerere University College of Health Sciences, Kampala, Uganda \\ ${ }^{2}$ RAND Corporation, Santa Monica, USA \\ Email: ${ }^{*}$ elialilia@yahoo.co.uk, ${ }^{*}$ elly@chs.mak.ac.ug
}

Received 9 February 2015; accepted 24 March 2015; published 25 March 2015

Copyright (C) 2015 by authors and Scientific Research Publishing Inc.

This work is licensed under the Creative Commons Attribution International License (CC BY). http://creativecommons.org/licenses/by/4.0/

cC) (i) Open Access

\section{Abstract}

Purpose: There is extensive evidence regarding the relationship between HIV related stigma and disclosure; however, the influence of depression in this relationship is not well understood, and thus is the focus of our analysis. Methods: Baseline data from a prospective longitudinal cohort of 798 HIV patients starting ART in Kampala, Uganda were examined. A staged-approach regression analysis was used to examine variables associated with HIV disclosure to most people (general disclosure) and disclosure to primary sex partner. Internalized HIV stigma plus demographic and background covariates were first entered into the model; the binary indicator of clinical depression was added on step two, followed by the addition of the interaction of stigma and depression in step three. Separate analyses were conducted for each of the two disclosure outcomes. Results: $39 \%$ indicated that they kept their HIV status as a secret from most people, while $19 \%$ of respondents with a regular sex partner had not disclosed their HIV status to the partner. In bivariate analysis, respondents who preferred to keep their HIV status as a secret from most people had higher internalized HIV stigma $(p<0.001)$ and depression $(p<0.01)$, and were more likely to be clinically depressed $(p<0.01)$ compared with others in the sample. Similarly, participants who had not disclosed their HIV status to their main sex partner had higher internalized HIV stigma (p $<0.01)$ and depression $(p<0.05)$, and were more likely to be clinically depressed $(p<0.01)$ compared with those who had informed their partner of their HIV status. The regression analysis revealed that internalized HIV stigma was strongly negatively correlated with disclosure to primary partner, while depression was not associated. In the regression analysis for general disclosure, both stigma and depression were negatively correlated with disclosure when the interaction term was included in the model. Further analysis showed that internalized HIV stigma was more strongly associated with general disclosure among participants who were not depressed. Conclusions: Although there was clearly a strong and consistent association between internalized HIV stigma and depression symptoms, the strong association between internalized HIV stigma and

\footnotetext{
${ }^{*}$ Corresponding author.
}

How to cite this paper: Okello, E.S., Wagner, G.J., Ghosh-Dastidar, B., Garnett, J., Akena, D., Nakasujja, N. and Musisi, S. (2015) Depression, Internalized HIV Stigma and HIV Disclosure. World Journal of AIDS, 5, 30-40. 
general disclosure among respondents who were not depressed indicated that HIV stigma was in itself remained a strong barrier to HIV disclosure. Therefore, interventions to reduce internalized HIV stigma may aid in efforts to decrease secondary transmission of HIV.

\section{Keywords}

\section{Depression, Internalized HIV Stigma, HIV Disclosure}

\section{Introduction}

Advances in diagnosis, treatment, and care of HIV infection including the use of antiretroviral therapy (ART) have transformed HIV/AIDS from an acute deadly illness to a manageable chronic illness. However, HIV remains a highly stigmatized disease and evidence shows that fear of stigma and discrimination may deter people from disclosing their HIV status to sexual partners, family and friends, which can impede prevention efforts such as promotion of HIV testing and condom use [1]-[6]. Disclosure to ones' significant others brings with it a host of potential consequences, some positive and some negative [5] [7]-[10]. The consequence theory of HIV disclosure suggests that disclosure is moderated by the consequences one anticipates resulting from the disclosure [11]. The theory postulates that persons with HIV are likely to reveal their HIV sero-status to significant others and sexual partners once the rewards for disclosing outweigh the associated costs. Derlega and others found that HIV-positive individuals used a selective disclosure process to reduce risks and increase benefits of disclosure [12]. Consequently, HIV-positive individuals disclose to those who pose little risk while avoiding disclosing to those who could harm them. Identifying factors associated with disclosure could help to inform how people living with HIV make disclosure decisions and thus how to support effective disclosure decision making and outcomes.

Studies that have documented prevalence of HIV disclosure in Sub-Saharan Africa have shown that the rates vary substantially in different populations. Studies focusing on rates of disclosure to primary sex partners have reported disclosure rates ranging from $16.7 \%$ to $90.2 \%$ in Tanzania, Kenya, Ethiopia, Rwanda, Burkina Faso, South Africa and the Democratic Republic of Congo [5] [9] [13]-[20]. Studies conducted in South Africa, Uganda and Ethiopia of more general disclosure, representing disclosure to people in one's social network including family, friends and others, reveal varying rates of between $18 \%$ to 95\% [6] [9] [21]-[23].

Studies on disclosure among persons living with HIV in Sub-Saharan Africa have identified several variables that have demonstrated correlation with disclosure. Several studies have indicated that HIV-infected individuals are more likely to disclose to a partner whom they know is HIV-positive than to an HIV-negative or unknown sero-status partner [24] [25]. Study by Mansergh and others found positive correlation between illness severity, length of time since HIV diagnosis and disclosure [26]. Research on partnership variables has demonstrated that "main/steady/regular" partnerships are more likely to involve disclosure than "other/casual/unfamiliar" partnerships [27] [28]. Another factor associated with disclosure was social support-individuals with high social support tend to disclose their result more often than those without such support [29]. Studies conducted in Tanzania and Ethiopia a strong association between prior communication about HIV testing with a partner and HIV-serostatus disclosure [10] [19].

Internalized stigma is believed to be a key determinant to disclosure. Several studies have attempted to assess the relationship between stigma and disclosure [9] [30]. There is a complex relationship between an individual's psychological state and feelings of being stigmatized and it's possible that depression may influence how internalized stigma relates to HIV disclosure. For example, if someone is depressed, the internalized stigma that they feel may impede even more so their comfort with disclosing their HIV status, whereas if the person is not depressed they may feel that they have adequate resources to cope with the risks associated with disclosure and thus assess the potential benefits of disclosure to outweigh the costs. However, how depression influences the relationship between internalized stigma and disclosure is not clear. Establishing this relationship is important if interventions that seek to promote disclosure and increase positive disclosure outcomes and secondary prevention of HIV are to be effective. This analysis focuses on the relationship between internalized HIV stigma and disclosure of HIV status, and how depression may influence this relationship. 


\section{Methods}

\subsection{Study Design and Setting}

Participants were enrolled in a longitudinal prospective cohort study designed to examine the effects of depression and antidepressant treatment on multiple health outcomes of ART. Participants were followed for one year from the start of ART, but the analysis for this paper was based solely on data collected at baseline, prior to the start of ART and antidepressant therapy. Participants were enrolled at four HIV clinics operated by Mildmay Uganda, in urban Kampala and the rural towns of Mityana, Naggalama and Mukono. These clinics generally serve clients in the lower socioeconomic strata and who work in the informal labor market.

\subsection{Sample}

Clients 18 years or older who had just been prescribed ART by their primary care provider, and agreed to start treatment, were eligible for enrollment. At each study clinic, the primary eligibility criteria for initiation of ART were a CD4 cell count $\leq 250$ cells $/ \mathrm{mm}^{3}$ or a diagnosis of WHO HIV disease stage III or IV (AIDS diagnosis). Between September 2010 and February 2011, clients were enrolled consecutively at the visit during which their eligibility for ART was determined. All participants were required to provide written informed consent. The study protocol was approved by Institutional Review Boards at RAND and Makerere University, as well as the Uganda National Council of Science and Technology.

\subsection{Measures}

All measures were interviewer-administered in Luganda, the most common language in this region of Uganda. The entire questionnaire was translated into Luganda using standard translation and back-translation methodology. Masters level psychologists were trained to administer the study assessments.

Depression: The 9-item Patient Health Questionnaire (PHQ-9) was used to measure the presence of depressive symptoms over the past 2 weeks. Each of the 9 items corresponds to the symptoms used to diagnose depression according to DSM (Diagnostic and Statistics Manual of Mental Disorders) criteria; responses to each item range from 0 "not at all” to 3 "nearly every day". Items were summed with a possible range of 0 - 27, and scores $>9$ signifies clinical depression and correspond highly to major depression as determined by a diagnostic clinical interview [31]. The items were divided into somatic (4 items: fatigue, difficulty sleeping, poor appetite/ overeating, psychomotor retardation) and cognitive symptoms (5 items: depressed mood, loss of interest, feeling bad about oneself, trouble concentrating, suicidal thoughts) of depression to create somatic and cognitive subscales, with each subscale being the sum of the included items. The PHQ-9 has been used successfully with HIV-infected individuals in other studies within Sub-Saharan Africa [32].

Internalized HIV stigma: was assessed with an 8-item scale developed by Kalichman and others [33]. Examples of items include "Being HIV positive makes me feel damaged" and "I am ashamed that I am HIV positive"; response options range from 1 “disagree strongly” to 5 “agree strongly”, and a mean item score is calculated. Higher scores represent greater stigma.

Disclosure: To measure general disclosure, participants were asked, "Do you generally keep your HIV status a secret from people?" A yes or no response was elicited. We also assessed disclosure to sex partners. Those who reported being married or in a committed relationship, or had a regular sex partner, were asked if they had disclosed to this partner. Responses options for both of these questions were "Yes" or "No". Participants who reported having casual sex partners (defined as a non-regular partner or partner not in a relationship with) in the past 6 months were asked, "To what extent did you disclose your HIV status to these other partners?” Response options included "did not disclose to any”, “disclosed to some”, and “disclosed to all”; a binary variable was then created to indicate whether or not all casual partners had been disclosed to.

Demographic and background characteristics: included age, sex, education level (classified as primary school or less vs. at least some secondary education), relationship status (binary indicator of whether the participant was married or in a committed relationship versus single, divorced or widowed), work status (binary indicator of any income or food generating activity in the past 7 days) and urban (those attending the Kampala clinic) versus rural (attending one of the other three clinics) location.

\subsection{Data Analysis}

Bivariate statistics (2-tailed independent t-tests; Chi Square tests) were used to examine the associations be- 
tween the binary HIV disclosure variables and measures of depression and internalized HIV stigma, as well as between depression and stigma (Pearson correlations). To examine how depression influences the relationship between internalized HIV stigma and HIV disclosure, we used a staged approach to our logistic regression analysis of variables associated with HIV disclosure. First, only internalized HIV stigma was included in the model in addition to demographic (age, sex, secondary education) and background (work status, clinic site) covariates. On the second step, the binary depression variable representing clinical depression was added to the model. Lastly, the interaction of stigma and depression was added to the model along with the main effects of stigma and depression. When the interaction term was significant, we conducted separate regression analyses for the clinically depressed and non-depressed subgroups to examine the relationship between internalized HIV stigma and disclosure, controlling for the covariates. Separate analyses were performed for general disclosure and disclosure to primary sex partner; analysis was not conducted for disclosure to casual partners because of the low number of participants with such partners and lack of significant bivariate correlates of such disclosure. For the inclusion of site in the regression models, the Kampala site served as the reference group.

\section{Results}

\subsection{Sample Description}

Table 1 lists the sample's demographic and medical characteristics. Two thirds of the study sample was female, few (15\%) had any secondary education, and most (66\%) were working in the past week. Just under one-third (32\%) was married, and another $12 \%$ were in a committed relationship; in addition, $24 \%$ were not married or in a committed relationship, but reported having a regular sex partner. The HIV status of the primary partner consisted of $46 \%$ being HIV-positive, $17.6 \%$ HIV-negative, and $36.6 \%$ being of unknown HIV status. Most of the total sample (86\%) had a CD4 count of 250 or less, but only 19\% had WHO disease stage III or IV. Mean PHQ9 score was $3.97(\mathrm{SD}=4.48)$; $12.5 \%$ had scores $>9$, which signifies clinical depression, and another $19.4 \%$ had minor depression (scores of 5 - 9).

Table 1. Sample characteristics.

\begin{tabular}{|c|c|}
\hline Variable & Total sample $(\mathrm{N}=798)$ \\
\hline \multicolumn{2}{|l|}{ Demographics } \\
\hline Mean age (SD) & $36.1(9.53)$ \\
\hline Male & $33.6 \%$ \\
\hline At least some secondary education & $15.3 \%$ \\
\hline Working (past 7 days) & $65.9 \%$ \\
\hline Married & $31.7 \%$ \\
\hline In committed relationship & $42.7 \%$ \\
\hline Residence (urban) & $43.0 \%$ \\
\hline CD4 count (mean; SD) & $155(86)$ \\
\hline AIDS diagnosis (WHO stage $3 / 4$ ) & $19.4 \%$ \\
\hline \multicolumn{2}{|l|}{ Mental health } \\
\hline Depression [PHQ-9; mean (SD)] & $3.97(4.48)$ \\
\hline Clinical depression (PHQ-9 > 9) & $12.5 \%$ \\
\hline \multicolumn{2}{|l|}{ Disclosure } \\
\hline Keep HIV status secret from most & $61.1 \%$ \\
\hline Disclosed to main (regular) sex partner & $81.4 \%(\mathrm{~N}=386)$ \\
\hline Disclosed to all non-regular sex partners & $33.9 \%(\mathrm{~N}=65)$ \\
\hline
\end{tabular}




\subsection{Prevalence of HIV Disclosure}

Regarding general disclosure of HIV status, 39\% indicated that they kept their HIV status a secret from most people. Of the 425 participants who had a main sex partner (includes married, in a committed relationship or has a regular sex partner), 81\% reported that they had disclosed their HIV status to this partner. Only 65 participants reported having casual sex partners in the 6 months prior to interview, of whom 34\% had disclosed their HIV status to all such partners.

\subsection{Bivariate Correlates of HIV Disclosure}

Participants who preferred to keep their HIV status a secret from most people had higher internalized HIV stigma $($ mean $=2.67$ vs. $1.61 ; \mathrm{p}<0.001$ ) and depression (mean $=4.32$ vs. $3.47 ; \mathrm{p}<0.01$ ), and were more likely to have clinical depression $(16.4 \%$ vs. $10.0 \%$; p < 0.01) compared to others in the sample. Similarly, participants who had not disclosed their HIV status to their main sex partner had higher internalized HIV stigma (mean = 2.68 vs. $2.21 ; \mathrm{p}<0.01$ ) and depression (mean $=4.82$ vs. 3.64; $\mathrm{p}<0.05$ ), and were more likely to have clinical depression $(16.5 \%$ vs. $12.4 \%$; p < 0.01 ) compared to those who had informed their partner of their HIV status. Also, the respondent was much more likely to have disclosed their HIV status to their primary partner if the partner was HIV-positive (100\%) or HIV-negative (95\%) compared to if the partner's status was unknown (52\%) $(p<0.000)$. Among the participants who had casual sex partners, those who had disclosed to all such partners did not differ significantly from those who had not disclosed to all partners with regard to internalized stigma, depression and presence of clinical depression.

Internalized HIV stigma was positively correlated with depression ( $\mathrm{r}=0.40$; $\mathrm{p}<0.001)$, and those with clinical depression had higher internalized stigma (mean $=3.06$ vs. 2.13; $\mathrm{p}<0.001$ ) compared to those who were not depressed (see Table 2).

\subsection{Multivariate Regression Analysis of the Influence of Depression on the Relationship between Internalized HIV Stigma and Disclosure}

In the analysis of general HIV disclosure (see Table 3), higher internalized HIV stigma was significantly associated with not disclosing HIV status to most people in step 1, as well as in step 2 with clinical depression added to the model; depression was not associated with disclosure in step 2. In the third step, with the stigma by depression interaction in the model, both internalized HIV stigma and clinical depression were negatively correlated with disclosure to most people, and the interaction term was positively associated with disclosure. In each step of the analysis, the only two covariates associated with general disclosure were work status and clinic site; working was associated with not disclosing to most people, while attending any of the three rural clinics was associated with having disclosed to most people in comparison to participants attending the Kampala site.

Table 2. Bivariate correlates of measures of HIV disclosure.

\begin{tabular}{|c|c|c|c|c|c|c|}
\hline & \multicolumn{2}{|c|}{$\begin{array}{l}\text { Do not keep HIV status } \\
\text { a secrete from most people }\end{array}$} & \multicolumn{2}{|c|}{$\begin{array}{l}\text { Disclose HIV status } \\
\text { to main partner }\end{array}$} & \multicolumn{2}{|c|}{$\begin{array}{l}\text { Disclose HIV status to all } \\
\text { non-regular partners }\end{array}$} \\
\hline & No & Yes & No & Yes & No & Yes \\
\hline Internalized HIV stigma & $2.67^{\mathrm{d}}$ & $1.61^{\mathrm{d}}$ & $2.68^{\mathrm{d}}$ & $2.21^{\mathrm{d}}$ & 2.51 & 2.24 \\
\hline Depression (PHQ-9 total) & $4.32^{\mathrm{c}}$ & $3.47^{c}$ & $4.82^{\mathrm{b}}$ & $3.64^{\mathrm{b}}$ & 3.40 & 4.27 \\
\hline Clinical depression & $16.4 \%^{\mathrm{b}}$ & $10.0 \%{ }^{\mathrm{b}}$ & $16.5 \%$ & $12.4 \%$ & $11.6 \%$ & $22.7 \%$ \\
\hline Mean age & $35.5^{\mathrm{a}}$ & $36.7^{\mathrm{a}}$ & $31.7^{\mathrm{d}}$ & $35.6^{\mathrm{d}}$ & $33.2^{\mathrm{b}}$ & $38.6^{\mathrm{b}}$ \\
\hline Male & $31.2 \%$ & $36.8 \%$ & $26.6 \%^{\mathrm{b}}$ & $41.9 \%{ }^{\mathrm{b}}$ & $51.2 \%$ & $59.1 \%$ \\
\hline Any secondary education & $15.4 \%$ & $13.9 \%$ & $18.8 \%$ & $16.2 \%$ & $13.5 \%$ & $15.0 \%$ \\
\hline Working & $66.6 \%$ & $64.6 \%$ & $68.4 \%$ & $71.7 \%$ & $67.4 \%$ & $63.6 \%$ \\
\hline
\end{tabular}

Note: ${ }^{\mathrm{a}} \mathrm{p}<0.10,{ }^{\mathrm{b}} \mathrm{p}<0.05,{ }^{\mathrm{c}} \mathrm{p}<0.01,{ }^{\mathrm{d}} \mathrm{p}<0.001$. 
Table 3. Regression analysis of correlates of HIV disclosure to most people.

\begin{tabular}{ccccccc}
\hline & \multicolumn{2}{c}{ Stigma only } & \multicolumn{2}{c}{ Stigma and depression } & \multicolumn{2}{c}{ Interaction: stigma w/depression } \\
\cline { 2 - 6 } & B & SE & B & SE & B & SE \\
\hline Internalized HIV stigma & $-2.19^{\mathrm{d}}$ & 0.18 & $-2.24^{\mathrm{d}}$ & 0.18 & $-2.42^{\mathrm{d}}$ & 0.21 \\
Clinical depression & - & - & 0.49 & 0.36 & $-2.04^{\mathrm{b}}$ & 1.04 \\
Stigma*depression & - & - & - & - & $1.07^{\mathrm{c}}$ & 0.41 \\
Age & -0.02 & 0.01 & -0.02 & 0.01 & -0.02 & 0.01 \\
Any secondary education & 0.07 & 0.28 & 0.09 & 0.28 & 0.11 & 0.28 \\
Male gender & 0.25 & 0.21 & 0.29 & 0.22 & 0.28 & 0.22 \\
Working & $-0.55^{\mathrm{b}}$ & 0.22 & $-0.54^{\mathrm{b}}$ & 0.22 & $-0.55^{\mathrm{b}}$ & 0.22 \\
Site 2 (Mukono) & $1.01^{\mathrm{d}}$ & 0.31 & $0.97^{\mathrm{c}}$ & 0.31 & $1.01^{\mathrm{c}}$ & 0.31 \\
Site 3 (Naggalama) & $0.78^{\mathrm{b}}$ & 0.32 & $0.76^{\mathrm{b}}$ & 0.32 & $0.79^{\mathrm{b}}$ & 0.32 \\
Site 4 (Mityana) & $1.21^{\mathrm{d}}$ & 0.25 & $1.16^{\mathrm{d}}$ & 0.26 & $1.21^{\mathrm{d}}$ & 0.26 \\
\hline
\end{tabular}

${ }^{\mathrm{a}} \mathrm{p}<0.10,{ }^{\mathrm{b}} \mathrm{p}<0.05,{ }^{\mathrm{c}} \mathrm{p}<0.01,{ }^{\mathrm{d}} \mathrm{p}<0.001 ; \mathrm{B}=$ beta; $\mathrm{SE}=$ standard error.

To better understand the relationship between the interaction of stigma and depression, and general disclosure, separate regression models were conducted for the subgroup of participants with clinical depression and those not depressed (see Table 4). In these models, only internalized HIV stigma and the demographic and background covariates were included as independent variables. Among the non-depressed patients, the odds of disclosing HIV status to most people was reduced by $91 \%$ [O.R. $(95 \% \mathrm{CI})=0.09(0.06,0.13)$ ] with each unit increase of internalized HIV stigma. While among the depressed subgroup, the relationship between stigma and general disclosure was still strong, but the magnitude of the relationship was less, as the odds of disclosure was reduced by $72 \%$ with each unit increase of stigma [O.R. $(95 \% \mathrm{CI})=0.28(0.14,0.57)]$.

In the analysis of HIV disclosure to primary partner (see Table 5), higher internalized HIV stigma was significantly associated with non-disclosure to the partner in all 3 steps, while neither clinical depression nor the interaction of stigma and depression was associated with disclosure. The odds of having disclosed to one's primary partner reduced by $55 \%$ to $62 \%$ for each unit increase of internalized HIV stigma. In each step of the analysis, the only two covariates associated with disclosure to partner were age and attending the Mukono clinic; older age was associated with having disclosed to one's partner, while attending the Mukono clinic was associated with nondisclosure to the partner in comparison to participants attending the Kampala site.

We did not include HIV status of the partner in this model, because the bivariate results showed that almost all respondents who knew the HIV status of their partner had disclosed; hence, with the strength of this relationship the inclusion of this variable in the model would have distorted the observed relationships between disclosure and the other variables. However, it is important to acknowledge that the regression model findings do not account for the HIV status of the partner.

\section{Discussion}

In our study a substantial proportion of respondents kept their HIV status a secret to most people or sexual partners. Non-disclosure of HIV status to most people was associated with higher internalized HIV stigma and depression while disclosing to most people was negatively correlated with both stigma and depression. However, in multivariate analysis, only stigma remained independently associated with both types of disclosure, while clinical depression was associated with non-disclosure to most people, but not disclosure to primary partner, and only when the interaction of stigma and depression were included in the model. Further analysis showed that internalized HIV stigma was more strongly associated with general disclosure among participants who were not depressed. This is contrary to our hypothesis that depression would increase a person's vulnerability to stigma, thus enhancing the stigma as a barrier to disclosure. The explanation to this finding may lie in the strong relationship between depression and internalized stigma, as both are types of mental health measures and the 
Table 4. Regression analysis of correlates of disclosure to most people among depressed and non-depressed patients.

\begin{tabular}{ccccc}
\hline & \multicolumn{2}{c}{ Among non-depressed } & \multicolumn{2}{c}{ Among depressed } \\
\cline { 2 - 5 } & $\mathrm{B}$ & $\mathrm{SE}$ & $\mathrm{B}$ & $\mathrm{SE}$ \\
\hline Internalized HIV stigma & $-2.45^{\mathrm{d}}$ & 0.21 & $-1.27^{\mathrm{d}}$ & 0.36 \\
Age & $-0.02^{\mathrm{a}}$ & 0.01 & -0.01 & 0.03 \\
Any secondary education & 0.12 & 0.29 & -0.46 & 1.44 \\
Male gender & 0.34 & 0.23 & -0.32 & 0.77 \\
Working & $-0.68^{\mathrm{c}}$ & 0.24 & 0.27 & 1.23 \\
Site 2 (Mukono) & $1.05^{\mathrm{c}}$ & 0.34 & 1.59 & 1.46 \\
Site 3 (Naggalama) & $0.76^{\mathrm{b}}$ & 0.34 & 2.33 \\
Site 4 (Mityana) & $1.14^{\mathrm{d}}$ & 0.28 & $25^{\mathrm{b}}$ & 1.14 \\
\hline
\end{tabular}

${ }^{\mathrm{a}} \mathrm{p}<0.10,{ }^{\mathrm{b}} \mathrm{p}<0.05,{ }^{\mathrm{c}} \mathrm{p}<0.01,{ }^{\mathrm{d}} \mathrm{p}<0.001 ; \mathrm{B}=$ beta; $\mathrm{SE}=$ standard error.

Table 5. Regression analysis of correlates of HIV disclosure to primary partner.

\begin{tabular}{cccccccc}
\hline & \multicolumn{2}{c}{ Stigma only } & \multicolumn{2}{c}{ Stigma and depression } & \multicolumn{2}{c}{ Interaction: stigma w/depression } \\
\hline & B & SE & B & SE & B & SE \\
\hline Internalized HIV stigma & $-0.43^{\mathrm{c}}$ & 0.16 & $-0.38^{\mathrm{b}}$ & 0.17 & $-0.45^{\mathrm{b}}$ & 0.19 & 1.25 \\
Clinical depression & - & - & -0.39 & 0.41 & -1.44 & 0.40 \\
Stigma*depression & - & - & - & - & 0.35 & 0.02 \\
Age & $0.05^{\mathrm{b}}$ & 0.02 & $0.05^{\mathrm{b}}$ & 0.02 & $0.05^{\mathrm{b}}$ & 0.37 \\
Any secondary education & -0.33 & 0.37 & -0.35 & 0.37 & -0.36 & 0.33 \\
Male gender & 0.42 & 0.32 & 0.43 & 0.33 & 0.41 & 0.06 & 0.31 \\
Working & 0.08 & 0.31 & 0.08 & 0.31 & $-0.99^{\mathrm{b}}$ & 0.39 \\
Site 2 (Mukono) & $-1.02^{\mathrm{c}}$ & 0.39 & $-1.00^{\mathrm{b}}$ & 0.39 & -0.33 & 0.47 \\
Site 3 (Naggalama) & -0.36 & 0.46 & -0.32 & 0.47 & -0.45 & 0.36 \\
Site 4 (Mityana) & -0.50 & 0.36 & -0.46 & 0.36 & & 0.39 \\
\hline
\end{tabular}

${ }^{\mathrm{a}} \mathrm{p}<0.10,{ }^{\mathrm{b}} \mathrm{p}<0.05,{ }^{\mathrm{c}} \mathrm{p}<0.01,{ }^{\mathrm{d}} \mathrm{p}<0.001 ; \mathrm{B}=$ beta; $\mathrm{SE}=$ standard error.

variance in disclosure that each explains likely overlaps. Therefore, when depression is not present (i.e., among those not depressed) it results in stigma explaining more of the disclosure variance as it does not have to share some of the explained variance with depression.

Previous research have shown that HIV positive individuals have difficulty disclosing their HIV status to significant others [34]. Varying rates of HIV non-disclosure ranging from $5.5 \%$ - 83\% have been reported in different sub populations across Africa [5] [10] [20] [22] [35]-[37]. HIV status disclosure is influences by the type of partnership [9] [20] [22], type of marriage [37], whether the person being disclosed to has a known positive status [20] [22] [38], the number of lifetime sex partners [13] and fears of abandonment, discrimination. Longitudinal studies have found that stigma is associated with lower likelihood of disclosure to sexual partners, friends, and family [39].

The extent to which people living with HIV/AIDS endorse the negative beliefs associated with HIV as true of themselves (internalize the HIV stigma), is an important consideration when examining reasons for nondisclosure. Previous research have shown that negative feelings for example shame about one's HIV status make it difficult for people living with HIV to tell others about their disease [40] [41]. Internalized stigma shapes when, how, and to whom to disclose [42] [43]. It is argued that self-disclosure decreases the ability to control second- 
hand disclosure by others, which may lead to stigmatizing consequences [44]. People living with HIV make disclosure decisions after weighing the pros and cons associated with serostatus disclosure [11] [45]. Hence nondisclosure according to Emlet, can be viewed as an act of protective silence [46].

In each step of the analysis in our study, the only two covariates associated with disclosure to partner were age and attending the Mukono clinic; older age was associated with having disclosed to one's partner, while attending the Mukono clinic, which is more rural clinic was associated with nondisclosure to the partner in comparison to participants attending the Kampala site.

Studies that have examined the relationship between age and HIV disclosure have presented mixed results. These findings are consistent with those previously reported by O'Brien [47], but contradicts findings of other studies conducted in Africa [14] [35] [48]. Lower rate of disclosure to sexual partner among younger individuals have been attributed to greater level of dependence on partner among younger individuals rendering them more susceptible to fears of isolation and of loss of economic support from a partner [5].

We found that people attending more rural clinics were less likely to disclosure HIV status compared to people attending urban clinics. This can either be due to higher level of stigma in the rural area or the communal nature of relationship which makes it difficult to control second hand disclosure. Studies that have assessed patterns of disclosure by residence have reported mixed findings. Some studies have attributed this pattern of disclosure to cultural norms where conservative nature of cultural norms that may contribute to stigmatization for people living with HIV and influence disclosure decisions [49] [50]. Other have focused on the size of the community where a person resides in relation to the level of disclosure stigma experienced [50] [51].

The results of this study are limited by several aspects of the study design. First, we used baseline data, in which, we did cross sectional analysis, hence using the current results, we unable to make definitive causal statements. Second, our sample consisted of a clinical sample of people living with HIV on antiretroviral treatment. All the participants were engaged in HIV care, and attending a program that requires its clients to have disclosed to someone in his/her social network before being prescribed antiretroviral therapy, so that they have someone who can be their treatment supporter. Such sample is likely to have lower levels of internalized stigma than HIV-infected individuals not in care. Therefore, the results cannot be considered representative of all persons living with HIV in Uganda or Sub-Saharan Africa.

\section{Conclusion}

In conclusion, our findings show a strong negative relationship between internalized HIV stigma and disclosure of HIV in general and to primary sexual partners. Depression, another indicator of psychological well-being and which was related to internalized stigma, was also negatively associated with disclosure, but only in bivariate analysis. Internal stigma is actually more strongly related to disclosure among non-depressed individuals, but it's not clear whether this is an artifact of the collinearity between depression and stigma, or that stigma has less of an influence on disclosure in the context of depression. What is clear is that internalized stigma appears to play a large role in HIV disclosure decision making and that interventions to reduce internalized HIV stigma may aid in efforts to increase HIV disclosure and thus decrease secondary transmission of HIV.

\section{Acknowledgements}

Funding for this research is from a grant from the National Institute of Mental Health (Grant No. 1R01MH 083568; PI: G. Wagner).

\section{References}

[1] Brouard, P. and Wills, C. (2006) A Closer Look: The Internalization of Stigma Related to HIV. Center for the Study of AIDS/University of Pretoria, and Caroline Wills, POLICY/South Africa. http://www.policyproject.com/pubs/generalreport/Internal_Stigma.pdf

[2] Campbell, C., et al. (2005) "I Have an Evil Child at My House": Stigma and HIV/AIDS Management in a South African Community. American Journal of Public Health, 95, 808-815. http://dx.doi.org/10.2105/AJPH.2003.037499

[3] Kinsler, J.J., et al. (2007) The Effect of Perceived Stigma from a Health Care Provider on Access to Care among a Low-Income HIV-Positive Population. AIDS Patient Care and STDs, 21, 584-592. http://dx.doi.org/10.1089/apc.2006.0202

[4] Letteney, S. and Laporte, H. (2004) Deconstructing Stigma: Perceptions of HIV-Seropositive Mothers and Their Dis- 
closure to Children. Social Work in Health Care, 38, 105-123. http://dx.doi.org/10.1300/J010v38n03_06

[5] Medley, A., et al. (2004) Rates, Barriers and Outcomes of HIV Serostatus Disclosure among Women in Developing Countries: Implications for Mother-to-Child Transmission Programmes. Bulletin of the World Health Organization, 82, 299-307.

[6] Ssali, S., et al. (2010) Reasons for Disclosure of HIV Status by People Living with HIV/AIDS and in HIV Care in Uganda: An Exploratory Study. AIDS Patient Care and STDs, 24, 675-681. http://dx.doi.org/10.1089/apc.2010.0062

[7] Hays, R., Turner, H. and Coates, T. (1992) Social Support, AIDS-Related Symptoms, and Depression among Gay Men. Journal of Consulting and Clinical Psychology, 60, 463-469. http://dx.doi.org/10.1037/0022-006X.60.3.463

[8] Klein, S., Karchner, W. and O’Connell, D. (2002) Interventions to Prevent HIV Related Stigma and Discrimination: Findings and Recommendations for Public Health Practice. Journal of Public Health Management \& Practice, 8, 4453. http://dx.doi.org/10.1097/00124784-200211000-00007

[9] Makin, J.D., et al. (2008) Factors Affecting Disclosure in South African HIV-Positive Pregnant Women. AIDS Patient Care STDs, 22, 907-916. http://dx.doi.org/10.1089/apc.2007.0194

[10] Maman, S., et al. (2003) High Rates and Positive Outcomes of HIV-Serostatus Disclosure to Sexual Partners: Reasons for Cautious Optimism from a Voluntary Counseling and Testing Clinic in Dar es Salaam, Tanzania. AIDS and Behavior, 7, 373-382. http://dx.doi.org/10.1023/B:AIBE.0000004729.89102.d4

[11] Serovich, J. (2001) A Test of Two Disclosure Theories. AIDS Education and Prevention, 13, 355-364. http://dx.doi.org/10.1521/aeap.13.4.355.21424

[12] Derlega, V., Lovejoy, D. and Winstead, B. (1998) Personal Accounts of Disclosing and Concealing HIV-Positive Test Results: Weighing the Benefits and Risks. In: Derlega, V. and Barbee, A., Eds., HIV Infection and Social Interaction, Sage, Newbury Park, 147-164.

[13] Antelman, G., Smith Fawzi, M.C., Kaaya, S., Mbwambo, J., Msamanga, G.I., Hunter, D.J. and Fawzi, W.W. (2001) Predictors of HIV-1 Serostatus Disclosure: A Prospective Study among HIV-Infected Pregnant Women in Dar es Salaam, Tanzania. AIDS, 15, 1865-1874. http://dx.doi.org/10.1097/00002030-200109280-00017

[14] Deribe, K., Woldemichael, K., Wondafrash, M., Haile, A. and Amberbir, A. (2008) Disclosure Experience and Associated Factors among HIV Positive Men and Women Clinical Service Users in Southwest Ethiopia. BMC Public Health, 8, 81.

[15] Farquhar, C., Mbori-Ngacha, D.A., Bosire, R.K., Nduati, R.W., Kreiss, J.K. and John, G.C. (2001) Partner Notification by HIV-1 Seropositive Pregnant Women: Association with Infant Feeding Decisions. AIDS, 15, 815-817. http://dx.doi.org/10.1097/00002030-200104130-00027

[16] Gari, T., Habte, D. and Markos, E. (2010) HIV Positive Status Disclosure among Women Attending Art Clinic at Hawassa University Referral Hospital, South Ethiopia. East African Journal of Public Health, 7, 87-91.

[17] Kassaye, K., Lingerh, W. and Dejene, Y. (2005) Associated Factors and Outcomes of Disclosing HIV-Sero Positive Status to Sexual Partners among Women in Mettu and Gore Towns, Illubabor Zone Southwest Ethiopia. The Ethiopian Journal of Health Development, 19, 126-131. http://dx.doi.org/10.4314/ejhd.v19i2.9981

[18] Lingappa, J.R., Lambdin, B., Bukusi, E.A., Ngure, K., Kavuma, L., Inambao, M., et al. (2008) Regional Differences in Prevalence of HIV-1 Discordance in Africa and Enrollment of HIV-1 Discordant Couples into an HIV-1 Prevention Trial. PLoS ONE, 3, e1411. http://dx.doi.org/10.1371/journal.pone.0001411

[19] Kiula, E.S., Damian, D.J. and Msuya, S.E. (2013) Predictors of HIV Sero Status Disclosure to Partners among HIVPositive Pregnant Women in Morogoro, Tanzania. BMC Public Health, 13, 433.

[20] King, R., Katuntu, D., Lifshay, J., Packel, L., Batamwita, R., Nakayiwa, S., et al. (2008) Processes and Outcomes of HIV Serostatus Disclosure to Sexual Partners among People Living with HIV in Uganda. AIDS and Behavior, 12, 232243. http://dx.doi.org/10.1007/s10461-007-9307-7

[21] Stutterheim, S.E., Bos, A.E., Pryor, J.B., Brands, R., Liebregts, M. and Schaalma, H.P. (2011) Psychological and Social Correlates of HIV Status Disclosure: The Significance of Stigma Visibility. AIDS Education and Prevention, 23, 382-392. http://dx.doi.org/10.1521/aeap.2011.23.4.382

[22] Vu, L., Andrinopoulos, K., Mathews, C., Chopra, M., Kendall, C. and Eisele, T.P. (2012) Disclosure of HIV Status to Sex Partners among HIV-Infected Men and Women in Cape Town, South Africa. AIDS and Behavior, 16, 132-138. http://dx.doi.org/10.1007/s10461-010-9873-y

[23] Osinde, M.O., Kakaire, O. and Kaye, D.K. (2012) Factors Associated with Disclosure of HIV Serostatus to Sexual Partners of Patients Receiving HIV Care in Kabale, Uganda. International Federation of Gynecology and Obstetrics, 118, 61-64.

[24] Niccolai, L.M., Dorst, D., Myers, L. and Kissinger, P.J. (1999) Disclosure of HIV Status to Sexual Partners: Predictors and Temporal Patterns. Sexually Transmitted Diseases, 26, 281-285.

http://dx.doi.org/10.1097/00007435-199905000-00008 
[25] Marks, G. and Crepaz, N. (2001) HIV-Positive Men’s Sexual Practices in the Context of Self-Disclosure of HIV Status. Journal of Acquired Immune Deficiency Syndromes, 27, 79-85. http://dx.doi.org/10.1097/00126334-200105010-00013

[26] Mansergh, G., Marks, G. and Simoni, J.M. (1995) Self-Disclosure of HIV Infection among Men Who Vary in Time since Seropositive Diagnosis and Symptomatic. AIDS, 9, 639-644. http://dx.doi.org/10.1097/00002030-199506000-00017

[27] Niccolai, L.M., King, E., D’Entremont, D. and Pritchett, E.N. (2006) Disclosure of HIV Serostatus to Sex Partners: A New Approach to Measurement. Sexually Transmitted Diseases, 33, 102-105. http://dx.doi.org/10.1097/01.olq.0000194591.97159.66

[28] Misovich, S.J., Fisher, J.D. and Fisher, W.A. (1997) Close Relationships and Elevated HIV Risk Behavior: Evidence and Possible Underlying Psychological Processes. Review of General Psychology, 1, 72-107. http://dx.doi.org/10.1037/1089-2680.1.1.72

[29] Degefa, A., Sanders, E.J., Mekonnen, Y., Messele, T., Wolday, D., Dorigo-Zetsma, W., et al. (2003) Knowledge and Attitudes towards Antiretroviral Therapy among Factory Workers Participating in a Cohort on HIV and AIDS, Addis Ababa, Ethiopia. Ethiopian Medical Journal, 41, 75-87.

[30] Steward, W.T., Chandy, S., Singh, G., Panicker, S.T., Osmand, T.A., Heylen, E. and Ekstrand, M.L. (2011) Depression Is Not an Inevitable Outcome of Disclosure Avoidance: HIV Stigma and Mental Health in a Cohort of HIV Infected Individuals from Southern India. Psychology Health and Medicine, 16, 74-85. http://dx.doi.org/10.1080/13548506.2010.521568

[31] Kroenke, K., Spitzer, R. and Williams, J. (2001) The PHQ-9: Validity of a Brief Depression Severity Measure. Journal of General Internal Medicine, 16, 606-613. http://dx.doi.org/10.1046/j.1525-1497.2001.016009606.X

[32] Monahan, P.O., Shacham, E., Reece, M., Kroenke, K., Ong’or, W.O., Omollo, O., et al. (2007) Validity/Reliability of PHQ-9 and PHQ-2 Depression Scales among Adults Living with HIV/AIDS in Western Kenya. Journal of General Internal Medicine, 24, 189-197. http://dx.doi.org/10.1007/s11606-008-0846-Z

[33] Kalichman, S.C., Simbayi, L.C., Jooste, S., Toefy, Y., Cain, D., Cherry, C. and Kagee, A. (2005) Development of a Brief Scale to Measure AIDS-Related Stigma in South Africa. AIDS \& Behavior, 9, 135-143. http://dx.doi.org/10.1007/s10461-005-3895-X

[34] Olley, B., Seedat, S. and Stein, D. (2004) Self-Disclosure of HIV Serostatus in Recently Diagnosed Patients with HIV in South Africa. African Journal of Reproductive Health, 8, 71-76. http://dx.doi.org/10.2307/3583180

[35] Gaillard, P., Melis, R., Mwanyumba, F., Claeys, P., Muigai, E., Mandaliya, K., et al. (2002) Vulnerability of Women in an African Setting: Lessons for Mother to Child HIV Transmission Programmes. AIDS, 16, 937-939. http://dx.doi.org/10.1097/00002030-200204120-00019

[36] Kilewo, C., Massawe, A., Lyamuya, E., Semali, I., Kalokola, F., Urassa, E., et al. (2001) HIV Counseling and Testing of Pregnant Women in Sub-Saharan Africa: Experiences from a Study on Prevention of Mother-to-Child HIV-1 Transmission in Dar es Salaam, Tanzania. Journal of Acquired Immune Deficiency Syndromes, 28, 458-462. http://dx.doi.org/10.1097/00042560-200112150-00009

[37] Brou, H., Djohan, G., Becquet, R., Allou, G., Ekouevi, D.K., Viho, I., et al. (2010) When Do HIV-Infected Women Disclose Their HIV Status to Their Male Partner and Why? A Study in a PMTCT Programme, Abidjan. PLoS Medicine, 4, e342.

[38] Gari, T., Habte, D. and Markos, E. (2010) HIV Positive Status Disclosure among Women Attending Art Clinic at Hawassa University Referral Hospital, South Ethiopia. East African Journal of Public Health, 7, 87-91.

[39] Chaudoir, S., Fisher, J. and Simoni, J. (2011) The Disclosure Process Model: A Review and Application of the Disclosure Processes Model. Social Science \& Medicine, 72, 1618-1629. http://dx.doi.org/10.1016/j.socscimed.2011.03.028

[40] Earnshaw, V.A. and Chaudoir, S.R. (2009) From Conceptualizing to Measuring HIV Stigma: A Review of HIV Stigma Mechanism Measures. AIDS and Behavior, 13, 1160-1177. http://dx.doi.org/10.1007/s10461-009-9593-3

[41] Lee, R.S., Kochman, A. and Sikkema, K.J. (2002) Internalized Stigma among People Living with HIV-AIDS. AIDS and Behavior, 6, 309-319. http://dx.doi.org/10.1023/A:1021144511957

[42] Derlega, V.J., Winstead, B.A., Greene, K., Serovich, J. and Elwood, W.N. (2002) Perceived HIV-Related Stigma and HIV Disclosure to Relationship Partners after Finding out about the Seropositive Diagnosis. Journal of Health Psychology, 7, 415-432. http://dx.doi.org/10.1177/1359105302007004330

[43] Clark, H.J., Lindner, G., Armistead, L. and Austin, B.J. (2003) Stigma, Disclosure, and Psychological Functioning among HIV-Infected and Non-Infected African-American Women. Women Health, 38, 57-71. http://dx.doi.org/10.1300/J013v38n04_04

[44] Ostrom Delaney, R.A., Serovich, J. and Lim, J. (2009) Psychological Differences between HIV-Positive Mothers Who Disclose to All, Some, or None of Their Biological Children. Journal of Marital and Family Therapy, 35, 175-180. http://dx.doi.org/10.1111/j.1752-0606.2009.00114.x 
[45] Armistead, L., Tannenbaum, L., Forehand, R., Morse, E. and Morse, P. (2001) Disclosing HIV Status: Are Mothers Telling Their Children? Journal of Pediatric Psychology, 26, 11-20. http://dx.doi.org/10.1093/jpepsy/26.1.11

[46] Emlet, C.A. (2007) Experiences of Stigma in Older Adults Living with HIV/AIDS: A Mixed-Methods Analysis. AIDS Patient Care and STDs, 21, 740-752. http://dx.doi.org/10.1089/apc.2007.0010

[47] O’Brien, M.E., Richardson-Alston, G., Ayoub, M., Magnus, M., Peterman, T.A. and Kissinger, P. (2003) Prevalence and Correlates of HIV Serostatus Disclosure. Sexually Transmitted Disease, 30, 731-735. http://dx.doi.org/10.1097/01.OLQ.0000079049.73800.C2

[48] Farquhar, C., Mbori-Ngacha, D.A., Bosire, R.K., Nduati, R.W., Kreiss, J.K. and John, G.C. (2001) Partner Notification by HIV-1 Seropositive Pregnant Women: Association with Infant Feeding Decisions. AIDS, 15, 815-817. http://dx.doi.org/10.1097/00002030-200104130-00027

[49] Nguyen, T. and Whetten, K. (2003) Is Anybody Out There? Integrating HIV Services in Rural Regions. Public Health Reports, 118, 3-9. http://dx.doi.org/10.1093/phr/118.1.3

[50] Mohammed, H. and Kissinger, P. (2006) Disclosure of HIV Serostatus to Sex Partners in Rural Louisiana. AIDS Care, 18, S62-S69. http://dx.doi.org/10.1080/09540120600839371

[51] Gonzalez, A., Miller, C.T., Solomon, S.E., Bunn, J.Y. and Cassidy, D.G. (2008) Size Matters: Community Size, HIV Stigma, \& Gender Differences. AIDS and Behavior, 13, 1205-1212. http://dx.doi.org/10.1007/s10461-008-9465-2 